\title{
Transformation to Pearlite from Work-hardened Austenite*
}

\section{By Minoru UMEMOTO,** Hideyuki OHTSUKA ${ }^{* * *}$ and Imao TAMURA**}

\section{Synopsis}

The effects of austenite deformation conducted below the recrystallization temperature on the subsequent isothermal transformation to pearlite in an eutectoid steel (SKD 6, H11) were quantitatively studied. The plastic deformation in the austenite condition was observed to lead to marked acceleration of austenite $\rightarrow$ pearlite transformation. This acceleration was found to be mostly caused by the increase in the nucleation rate but not by the increase in the groweth rate.

The increase in the nucleation rate per unit volume of specimen was attributed (1) to the increase in the austenite grain surface by the elongation of grains, (2) to the increase in the nucleation rate per se per unit area of grain surface, and (3) to the formation of additional nucleation sites such as annealing twin boundaries, deformation bands, etc. Among these the increase in the nucleation rate per se per unit area of grain surface was found to have the largest effect on the acceleration of transformation by deformation in the steel studied.

The effects of rolling reduction and austenite grain size on the acceleration mechanism of transformation were discussed based on the derived kinetic equation.

\section{Introduction}

The development of strong and tough steels had been achieved mainly by controlling the microstructures with the alloy designing and thermal treatments. In the mean while, the deformation had been performed mainly to control the shape of material but not to control the microstructure. It is only in recent years that these two fields, i.e., controlling of microstructures and that of shapes, have been deliberately combined to lead to development of thermomechanical treatments.

There are two thermomechanical treatments which are of a great interest and industrial importance; these are ausforming ${ }^{1)}$ and controlled rolling. ${ }^{2}$ ) The controlled rolling is classified into three types depending on the deformation temperature, ${ }^{3,4)}$ i.e., (1) deformation above the recrystallization temperature, (2) deformation below the recrystallization temperature, and (3) deformation at the $(\alpha+\gamma)$ two phase temperature range. Among these, the deformation below the recrystallization temperature and that at the $(\alpha+\gamma)$ two phase temperature range have large influence on the subsequent diffusional transformations.
The development of strong and tough steels is expected to be accomplished mostly by applying the controlled rolling below the recrystallization temperature. However, the transformation kinetics from the work-hardened austenite, which are the basis of such thermomechanical treatment, have not been well understood quantitatively. Thus, the present study was undertaken to make clear the effect of austenite deformation to be conducted below the recrystallization temperature on the subsequent diffusional transformation. The pearlitic transformation from work-hardened austenite was investigated because of the simplicity in the transformation kinetics.

\section{Experimental Procedure}

The steel used in the present study was SKD 6 (nearly eutectoid) with a chemical composition listed in Table 1. This steel was selected for the present study since the pearlitic transformation is relatively simple in kinetics and the transformation rate is slow so that the error in time which may be introduced by handling specimen from one temperature to another can be neglected. This steel is not directly related with the controlled rolling, but the experimental results and analyses to be gained should prove to be useful to obtain the basic concepts of transformation kinetics from work-hardened austenite.

Figure 1 shows the TTT diagram of the non-deformed SKD 6 steel after austenitized at $1000{ }^{\circ} \mathrm{C}$ for 30 min determined by using an automatic quench dilatometer (Formastor-F). The curves in the figure indicate the times for pearlite fraction to reach 0.1, 0.5 and 0.9 , respectively. It is seen from Fig. 1 that the pearlite transformation of the steel SKD 6 exhibits typical $\mathrm{C}$ curve with the nose temperature at $720^{\circ} \mathrm{C}$ and the bay inferred to be at around $650^{\circ} \mathrm{C}$.

Specimens were homogenized at $1200^{\circ} \mathrm{C}$ for $20 \mathrm{~h}$ and hot and cold rolled to sheets of $4 \mathrm{~mm}$ thick. These were cut into pieces of $70 \times 8 \times 4 \mathrm{~mm}$. Figure 2 schematically shows the thermal treatments applied in the present study. Specimens were austenitized at $1100^{\circ} \mathrm{C}$ for $30 \mathrm{~min}$, quenched into a salt bath kept at the bay temperature of $650{ }^{\circ} \mathrm{C}$ and held for

Table 1. Chemical composition of SKD6. (wt\%)

\begin{tabular}{cccccccccccc}
\hline $\mathrm{C}$ & $\mathrm{Si}$ & $\mathrm{Mn}$ & $\mathrm{P}$ & $\mathrm{S}$ & $\mathrm{Ni}$ & $\mathrm{Cr}$ & $\mathrm{Mo}$ & $\mathrm{V}$ & $\mathrm{Cu}$ & $\mathrm{Fe}$ \\
\hline 0.35 & 0.89 & 0.43 & 0.013 & 0.007 & 0.006 & 5.50 & 1.20 & 0.52 & 0.03 & bal. \\
\hline
\end{tabular}

* Presented to the 104th ISIJ Meeting, September 1982, S1384, at Hokkaido University in Sapporo. Manuscript received January 13, 1983. (C) 1983 ISIJ

** Department of Metal Science and Technology, Kyoto University, Yoshida-honmachi, Sakyo-ku, Kyoto 606.

*** Graduate School, Kyoto University, Yoshida-honmachi, Sakyo-ku, Kyoto 606 


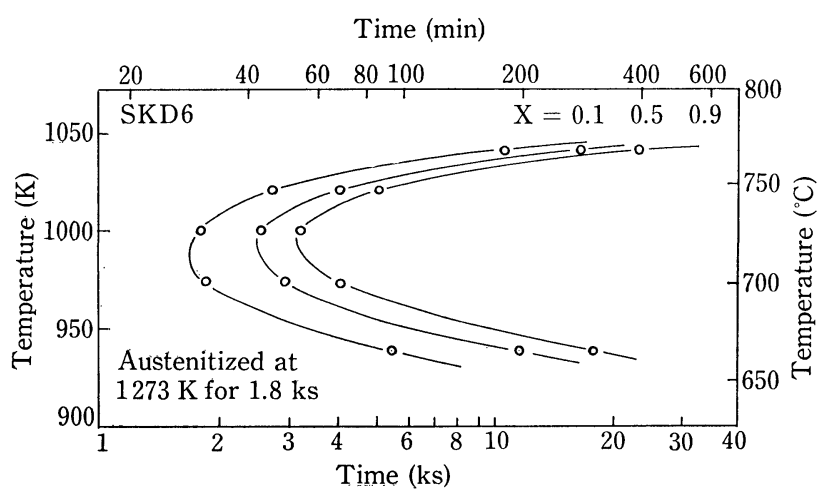

Fig. 1. TTT diagram of SKD6 for pearlite fraction of $0.1,0.5$ and 0.9 .

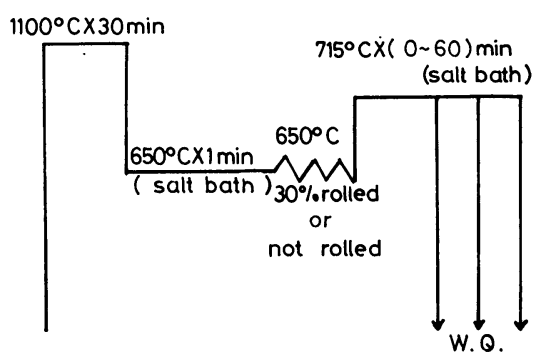

Fig. 2. Patterns of heat treatments.

about $1 \mathrm{~min}$. A group of specimens was then rolled to $30 \%$ reduction by a single pass, up quenched into a salt bath kept at $715^{\circ} \mathrm{C}$, held for various periods to transform into pearlite, and water quenched. It was confirmed from the optical microscope observation that by this $30 \%$ rolling austenite was workhardened but recrystallization did not start before or during transformation. Another group of specimens was transferred directly from the salt bath kept at $650{ }^{\circ} \mathrm{C}$ to another salt bath kept at $715^{\circ} \mathrm{C}$ without any deformation, held for the same period of time with the deformed specimens, and water quenched.

After water quenching, the specimens for optical microscope observations were prepared in pieces of $15 \times 8 \times 4 \mathrm{~mm}$ from the deformed and non-deformed samples, polished deep enough to remove the surface layer, and etched with $5 \%$ nital and the hydrofluoric acid solution before serving to observation. Here $5 \%$ nital was used to reveal the pearlite nodules, and hydrofluoric acid solution was used to reveal the prior austenite grain boundaries and lath martensite structure. The effects of austenite deformation on the subsequent pearlite reactions were studied by comparing the microstructures in the deformed and non-deformed specimens. The pearlite fraction was measured by point counting method.

\section{Experimental Results}

\section{Behavior of Transformation to Pearlite}

Photograph 1 shows the progress of transformation in the deformed and non-deformed specimen at $715^{\circ} \mathrm{C}$. Photographs 1 (a), (c), (e) and (g) are the optical micrographs taken from the non-deformed specimens, and (b), (d), (f) and (h) are those taken from the deformed specimens after transformed at $715^{\circ} \mathrm{C}$ for $8,20,30$ and $60 \mathrm{~min}$, respectively. The dark etched regions are pearlite and lightly etched regions are lath martensite formed during the final water quench. The rolling direction in the pictures here and hereafter is parallel to the horizontal, if not specified otherwise. It is seen that the pearlite reaction in the non-deformed specimen had started by holding for about $20 \mathrm{~min}$ at $715^{\circ} \mathrm{C}$, but in the deformed specimen it started by holding for only about $8 \mathrm{~min}$. The deformation of austenite clearly accelerated the pearlite transformation.

In the early stage of transformation, relatively large isolated pearlite nodules were seen in the nondeformed specimen as is seen in Photo. 1 (e), while in the deformed specimens thin pearlite films were observed along the austenite grain boundaries as is shown in Photo. 1 (d). Photograph 2 is the enlarged micrograph of the deformed specimen showing the pearlite nodules on the austenite grain boundaries in a very early stage of transformation. It is seen that individual pearlite nodules are growing into austenite grains from the boundaries. This indicates that the thin pearlite films observed in Photo. 1 (d) were produced by a large number of pearlite nodules formed close to each other along the grain boundaries and then got contacted by their further growth, but not by the preferential growth of a small number of pearlite nodules along the grain boundaries.

In the middle stage of transformation, the pearlite nodules are granular and austenite grain boundaries are not completely occupied in the non-deformed specimen (Photo. $1(\mathrm{~g})$ ). This indicates that in the pearlite transformation of undeformed steel both the nucleation and the growth are important. While in the deformed specimen (Photo. 1 (f)) almost all the austenite grain boundaries were occupied by the pearlite nodules. In this case the transformation proceeds mostly by the thickening (growth) of the pearlite films and the further nucleation hardly takes place.

\section{Nucleation Sites in the Deformed Specimen}

As was shown in Photo. 1 there are clear differences in the behaviors of pearlite transformation between the deformed and non-deformed specimens. In the non-deformed specimens austenite grain boundaries are the predominant nucleation sites of pearlite but in the deformed specimens nucleation occurs not only on the austenite grain boundaries but also inside the grains.

Photograph 3 shows various kinds of nucleation sites of pearlite observed in the deformed specimens. Photograph 3 (a) shows the pearlite nodules nucleated at austenite grain boundaries. In the early stage of transformation the nucleation occurs mostly on austenite grain boundaries.

Photograph 3 (b) shows the pearlite nodules nucleated at the annealing twin boundaries. As the transformation progresses, the pearlite tends to nucleate at the annealing twin boundaries. Waker and Honeycombe $^{5)}$ observed the ferrite nucleation also occurs 

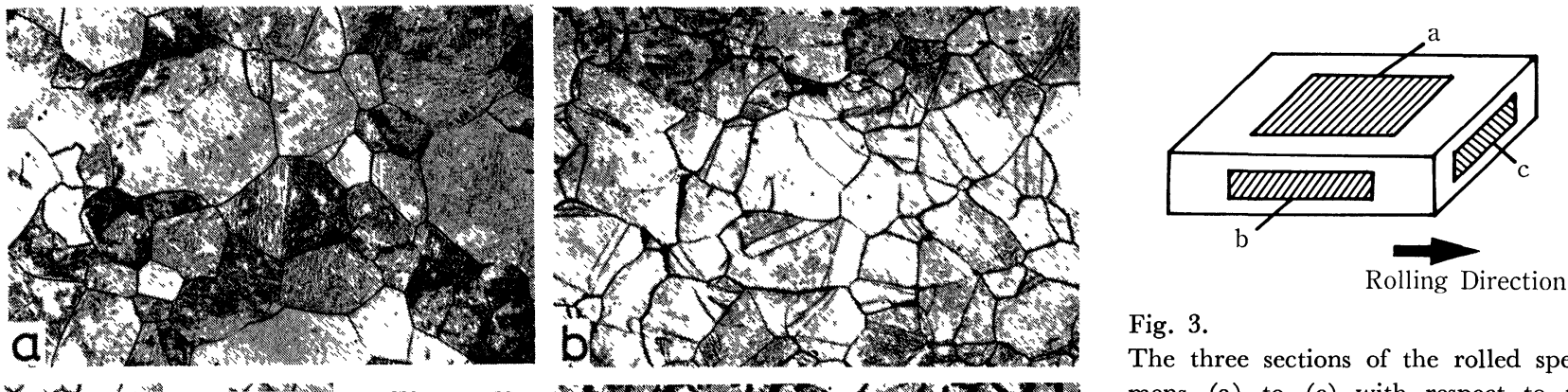

Fig. 3.
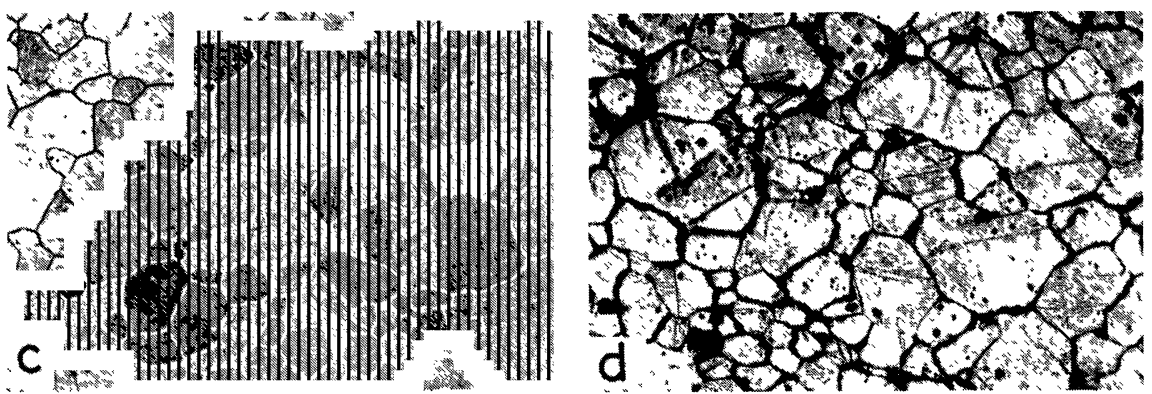

The three sections of the rolled specimens (a) to (c) with respect to the rolling direction.
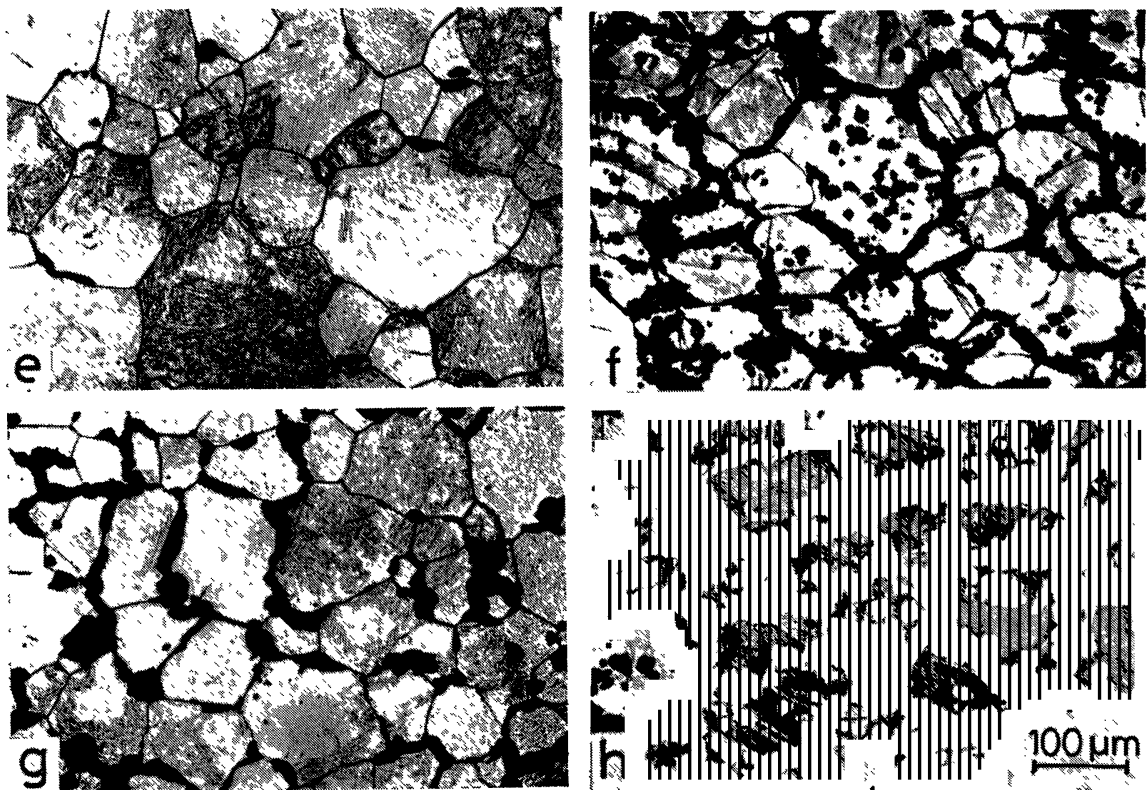

(a) Not rolled, $8 \mathrm{~min}$

(b) $30 \%$ rolled, $8 \mathrm{~min}$

(c) Not rolled, $20 \mathrm{~min}$

(d) $30 \%$ rolled, $20 \mathrm{~min}$

(e) Not rolled, $30 \mathrm{~min}$

(f) $30 \%$ rolled, $30 \mathrm{~min}$

(g) Not rolled, $60 \mathrm{~min}$

(h) $30 \%$ rolled, $60 \mathrm{~min}$

Pictures were taken from the section (a) shown in Fig. 3.

Photo. 1. Optical micrographs showing the progress of transformation to pearlite at $715^{\circ} \mathrm{C}$.

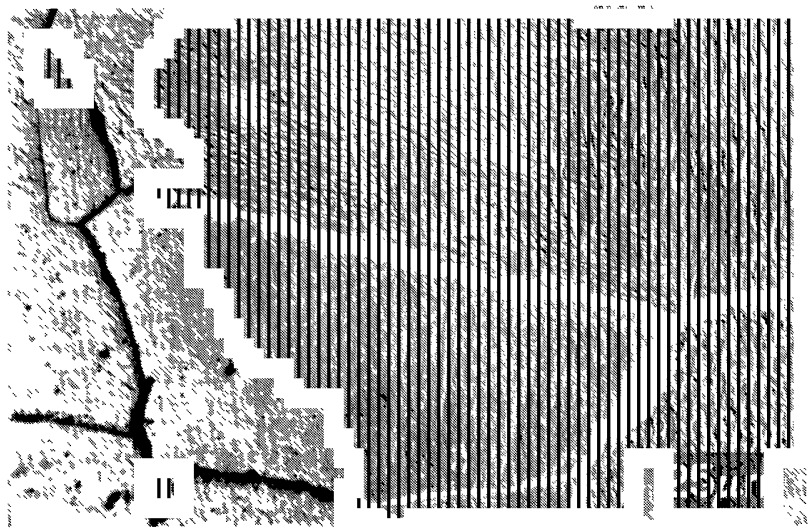

Photo. 2. Optical micrograph taken from the deformed specimen showing small pearlite nodules nucleated on the austenite grain boundaries in the early stage of transformation. Specimen was held for $10 \mathrm{~min}$ at $715^{\circ} \mathrm{C}$ after $30 \%$ rolling. Pictures were taken from the section (a) shown in Fig. 3. on austenite twin boundaries in the steel En 24 after hot deformation of austenite.

Photograph 3 (c) shows the pearlite nodules nucleated at the deformation bands. The nature of deformation bands is not well understood yet, but Kozasu et $a l .^{6)}$ reported that the density of the deformation bands depends primarily on the degree of rolling reduction and is barely affected by temperature and strain rate of deformation.

Photograph 3 (d) shows pearlite nodules nucleated intragranularly. The austenite grain at the central region does not show any deformation bands but many pearlite nodules were observed nucleated within the grains.

In summary, in the deformed specimen annealing twin boundaries and deformation bands were observed to act as the additional nucleation sites, and also the intragranular nucleation was observed besides the nucleation at austenite grain boundaries. 

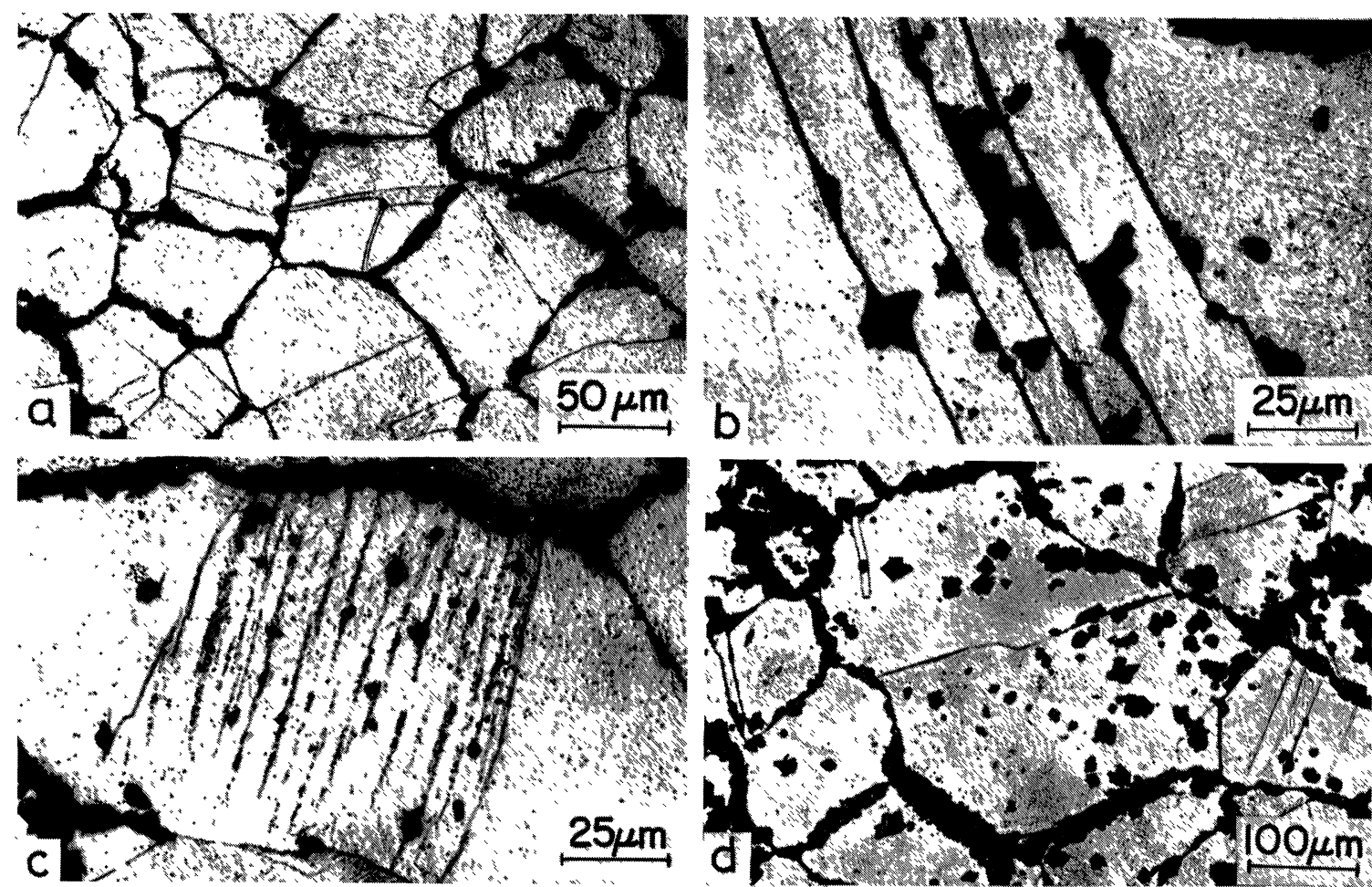

(a) Nucleation at grain boundaries (c) Nucleation on deformation bands Pictures were taken from the section (a) shown in Fig. 3.

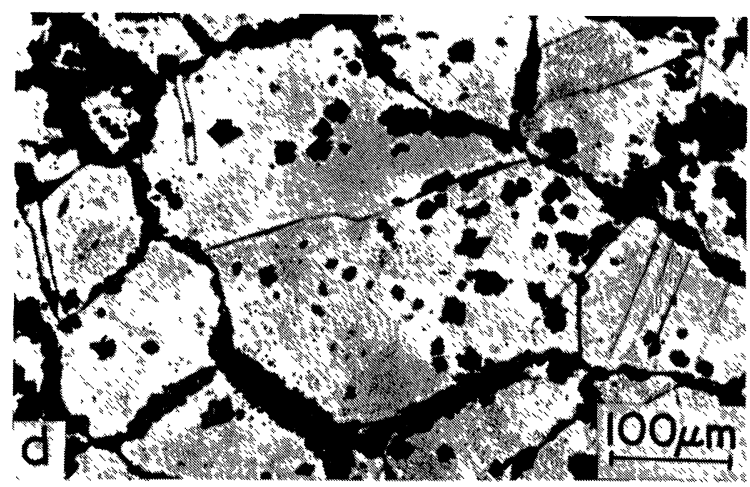

(b) Nucleation on annealing twin boundaries

(d) Nucleation inside the grains

Photo. 3. Optical micrographs showing the various types of nucleation sites observed in the deformed specimen.

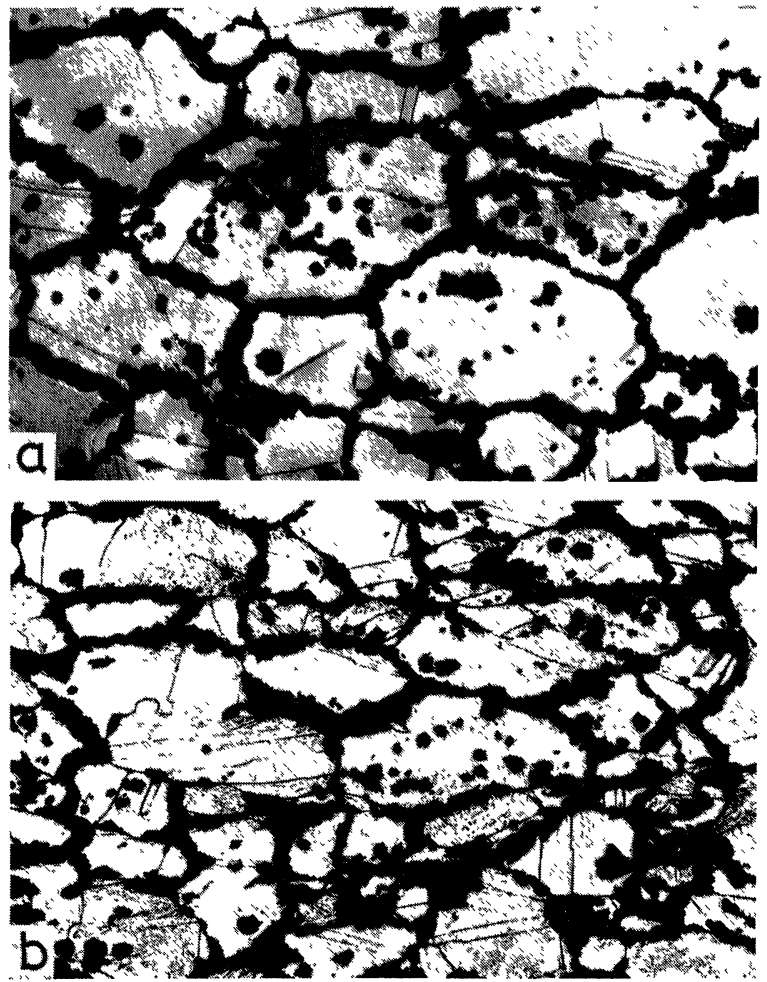

3. The Effect of Rolling Direction on the Appearance of Pearlite Nodules

Photograph 4 shows the effect of rolling direction on the appearance of pearlite nodules. Pictures were taken from the specimen rolled $30 \%$ in reduction at $650^{\circ} \mathrm{C}$ and transformed at $715^{\circ} \mathrm{C}$ for $30 \mathrm{~min}$. Photographs 4 (a) to (c) correspond to the sections (a) to (c)

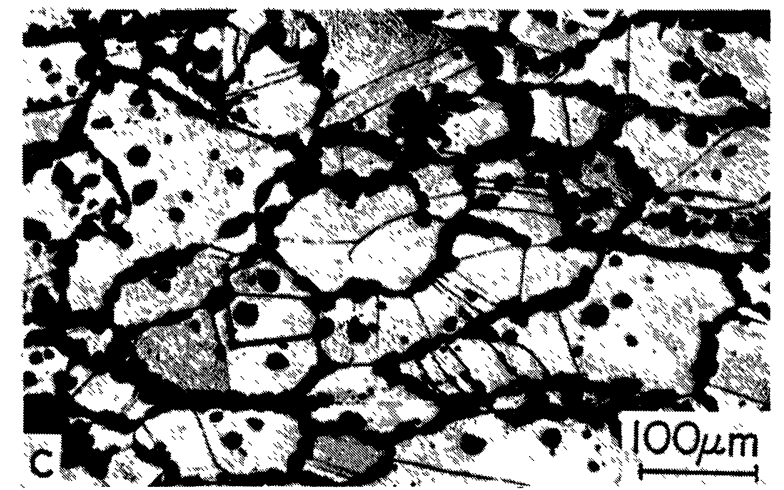

Photo. 4.

Optical micrographs showing that the effect of rolling direction on the appearance of pearlite nodules in the deformed specimens is small. (a), (b) and (c) correspond to the sections (a), (b) and (c) shown in Fig. 3, respectively.

shown in Fig. 3, respectively. In these pictures it is seen that austenite grains were elongated along the rolling direction (horizontal direction). It was known $^{7)}$ that under applied stress the pearlite nodules grow preferentially in the direction perpendicular to the tensile axis. However, as is seen in Photo. 4, no preferential growth direction were observed in the pearlite nodules formed from the work-hardened austenite.

\section{Growth Rate of a Pearlite Nodule}

To obtain the growth rate of pearlite, the maximum nodule radii were measured in specimens transformed 
for various periods of time at $715^{\circ} \mathrm{C}$. Figure 4 shows the results as a function of holding time. In this figure $O$ marks indicate the data taken from nondeformed specimens, and $\times$ marks indicate those obtained from the deformed specimens. As is seen, the data obtained for both the deformed and nondeformed specimens lie on a same straight line. From the slope of this line the growth rate for both the deformed and the non-deformed specimens was obtained as $0.31 \mu \mathrm{m} / \mathrm{min}$.

Weissenberg and Hornbogen ${ }^{8)}$ suggested that when new phase forms with diffusional transformation from the work-hardened parent phase, the growth rate of new phase will be accelerated by the difference in the dislocation density between in the matrix and in the new phase. However, even if we assume that the dislocation density in the work-hardened austenite is as high as $10^{10} \mathrm{~cm}^{-2}$, the free energy change by the disappearance of these dislocations is at the most $1 \mathrm{cal} / \mathrm{mol}$, a value which is considerably smaller than the usual chemical driving force for pearlite (about $60 \mathrm{cal} / \mathrm{mol}$ when the supercooling is $\left.50^{\circ} \mathrm{C}^{9}\right)$. Since the growth rate of pearlite is known to be quadratic with respect to the transformation driving force ${ }^{10}$ ) (chemical plus non-chemical), it may be concluded that the effect of the dislocation density on the acceleration of growth rate is small.

\section{Discussion}

\section{The Mechanism of Transformation Acceleration by Deformation}

The present investigation showed that plastic deformation in the austenite condition led to marked acceleration of austenite-pearlite transformation. Microscopic examination revealed that there was no detectable change in the growth rate by deformation. Thus it can be said that the acceleration of austenite pearlite transformation is caused mainly by the increase in the nucleation rate. From the optical microscope observation (Photos. 1 to 3), the dominant nucleation site of pearlite in a deformed specimen may be considered as the grain surface among the potential nucleation sites of a grain boundary, i.e., surface, edge and corner. Of course the grain boundary surface of a deformed specimen cannot be homogeneous, but when the density of potential nucleation sites is high enough, grain surface can be considered as homogeneous for the nucleation of pearlite.

The increase in the nucleation rate per unit volume of specimen by the deformation in austenite condition is considered to be attributed to the following three factors:

1) the increase in the austenite grain surface area per unit volume of the specimen by the elongation of grains,

2) the increase in the nucleation rate per se per unit area of austenite grain surface, and

3) formation of additional nucleation sites such as deformation bands.

These three factors are illustrated separately in

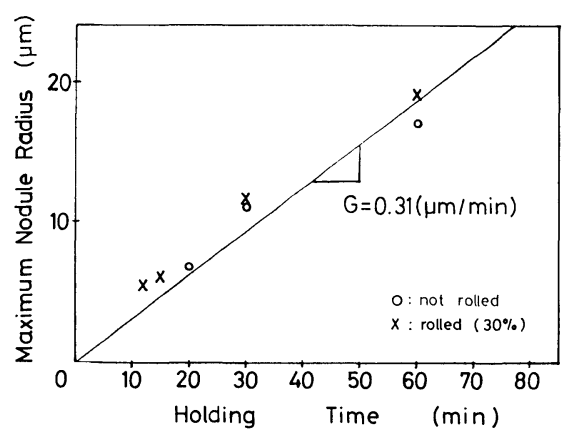

$O$ : Non-deformed specimens

$x$ : Deformed specimens

Fig. 4. Observed maximum radii of pearlite nodule as a function of holding time at $715^{\circ} \mathrm{G}$.

(a)

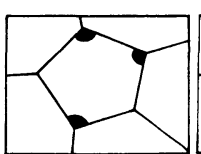

(b)

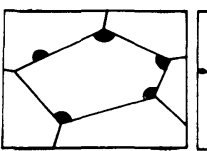

(c)

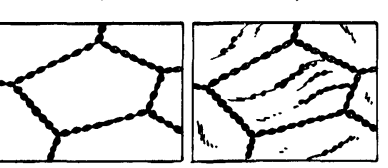

(a) The initial, non-deformed condition

(b) A deformed condition in which the grains are elongated only

(c) A deformed condition in which grains are elongated and the rate of nucleation on grain boundary is increased.

(d) A deformed condition in which grains are elongated, the rate of nucleation on grain boundary is increased and deformation bands are produced on which to invite further nucleation.

Fig. 5. An early stage of pearlite transformations in 4 different austenite conditions.

Fig. 5. In Fig. 5, an early stage of pearlite transformation in each austenite condition is drawn schematically to express the difference in austenite conditions clearly: (a) shows the initial, non-deformed condition, (b) shows a deformed condition in which the grains are elongated but nucleation rate per unit area of grain boundary is not altered and deformation bands are not produced, (c) shows a deformed condition in which grains are elongated and nucleation rate per unit area of grain boundary is increased but deformation bands are not produced, and (d) shows a deformed condition where grains are elongated, nucleation rate is increased and deformation bands are produced on which to invite further nucleation.

About the kinetics of grain boundary nucleation reactions, Cahn'11) showed that when the nucleation rate per unit area of austenite grain surface $I_{g \cdot b}$ and the growth rate $G$ are constant with time, the transformed fraction $X$ for the reaction in which the new phase nucleates on grain boundary surface is given as

$$
\begin{aligned}
X= & 1-\exp \left\{-2 S_{g^{\cdot b}} G t \int_{0}^{1}\left(1-\exp \left\{-\pi I_{g^{\cdot b}} G^{2} t^{3}\right.\right.\right. \\
& \left.\left.\left.\times\left[\left(1-x^{3}\right) / 3-x^{2}(1-x)\right]\right\}\right) d x\right\} \ldots \ldots \ldots \ldots \ldots \ldots \ldots \ldots \ldots \ldots \ldots \ldots
\end{aligned}
$$

where $S_{g \cdot b}$ is the austenite grain surface area per unit 
volume of specimen, and $x=y /(G t)$ where $y$ is a distance from boundary. $S_{g \cdot b}$ is given by the average intercept length of grain boundaries on the plane of polish, $\bar{l}$, as $\left.{ }^{12}\right)$

$$
S_{g \cdot b}=\frac{2}{\bar{l}}
$$

The ASTM nominal diameter $D$ is related with $\bar{l}$ as $^{13)}$

$$
D=1.1225 \bar{l}
$$

Based on Eq. (1), the effect of deformation on the transformation kinetics will be discussed considering the deformation effect on each of the above three factors. Here, it is to be borne in mind that a previous investigation ${ }^{14)}$ showed that the predominant nucleation site for pearlite in the non-deformed SKD 6 steel was the austenite grain edges. However, to make the comparison easy, the nucleation rate of pearlite in a non-deformed specimen was measured also in terms of per unit area of grain boundary surface.

\section{The Effect of Rolling Reduction on the Grain Boundary Surface Area}

The surface area of austenite per unit volume of the specimen increases by elongation of grains. For simplicity, assume that the initial austenite grains are spherical with unit radius as shown in Fig. 6(a). (This is equivalent to assuming that the austenite grain boundaries are consisted of planar segments randomly distributed, as regards the rolling direction.) By applying the rolling with reduction $p$, their shape becomes ellipsoid as shown in Fig. 6(b). The surface area of a grain before rolling is given as

$$
S_{g}^{0} \cdot b=4 \pi
$$

The surface area of a grain after rolling to reduction $p$ is given as

$$
\begin{aligned}
S_{g \cdot b}(p)= & \int_{-1 / 1-p}^{1 / 1-p}\left[\left\{4 x \int_{0}^{\pi / 2} \sqrt{1-\left(2 p-p^{2}\right) \sin ^{2} \theta} d \theta\right\}\right. \\
& \left.\times \sqrt{\frac{x^{2}(1-p)^{6}}{1-x^{2}(1-p)^{2}}+1}\right] d x \ldots \ldots \ldots \ldots \ldots \ldots \ldots \ldots \ldots \ldots \ldots \ldots
\end{aligned}
$$

The ratio of the surface area before rolling to that of after, $q\left(=S_{g \cdot b}(p) / S_{g \cdot b}^{0}\right)$, is plotted in Fig. 7 as a function of rolling reduction $p$ and true strain $\varepsilon$. Since the volume of the sphere shown in Fig. 6(a) is equal to that of the ellipsoid shown in Fig. 6(b), the ratio $q$ in Fig. 7 is equal to that pertaining to grain surface areas per unit volume before and after rolling. It is seen that the increase in the grain surface area per unit volume with the increase in $p$ is quite small when $p$ is small (such as $30 \%$ reduction). At $p=0.3$, which is the reduction applied in the present study, $q$ is equal to 1.04 .

\section{The Effect of Austenite Deformation on the Nucleation Rate on Grain Boundaries}

As was shown in Photo. 1, a considerable difference was observed in the transformation behavior of pearlite between the deformed and non-deformed specimens. In the non-deformed specimens, a small number of lonely (i.e., isolated each other) relatively large size pearlite nodules were observed in the middle stage of transformation. While, in the deformed specimens a large number of pearlite nodules were observed in a very early stage of transformation, and these turned out to be the pearlite films along the austenite grain boundaries. Consequently in the nondeformed specimen austenite grain boundaries was able to remain untransformed after $60 \mathrm{~min}$ of transformation (see Photo. $1(\mathrm{~g})$ ), but in the deformed specimen (30\% rolling) almost all the grain boundaries were occupied by pearlite only by $30 \mathrm{~min}$ of transformation at $715^{\circ} \mathrm{C}$ (see Photo. 1(f)). These indicate that the nucleation rate on the grain boundaries is considerably increased by deformation.

The nucleation rates at grain boundary in the deformed and non-deformed specimen were estimated as follows. Using the deformed specimen transformed $30 \mathrm{~min}$ at $715^{\circ} \mathrm{G}$ and the non-deformed specimen transformed $60 \mathrm{~min}$ at $715^{\circ} \mathrm{C}$, the linear intercept lengths and the transformed fractions of pearlite nucleated at the grain boundaries were measured. The nucleation rates per unit area of austenite grain surface were calculated from Eq. (1) using the values

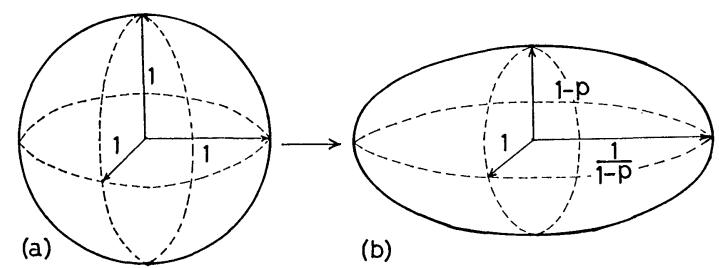

(a) Before rolling (sphere)

(b) After rolling (ellipsoid)

Fig. 6. The shape change of an austenite grain by the rolling with reduction $p$.

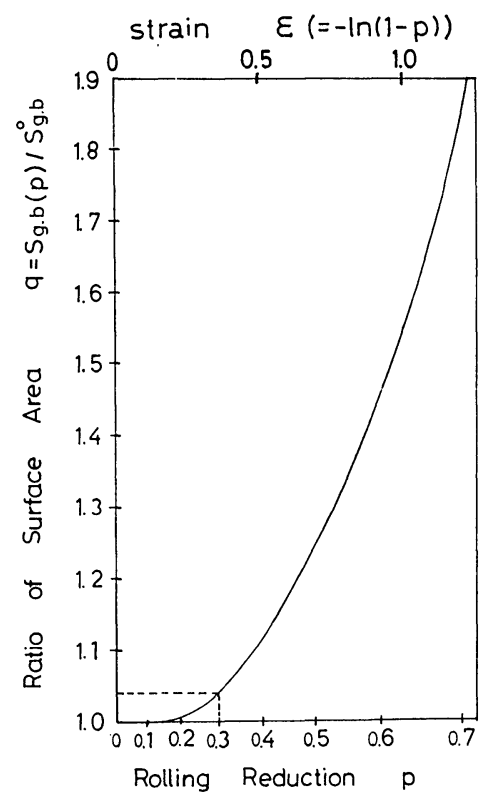

Fig. 7. The ratio of austenite grain surface area before rolling to that of after as a function of rolling reduction $p$. 
listed in Table 2. (In Table 2, the average linear intercept length in the deformed specimen is larger than that of the non-deformed specimen since the grain size was measured on the section (a) denoted in Fig. 3.) The $I_{g \cdot b}$ values obtained were $20.3 \mathrm{~mm}^{-2}$. $\min ^{-1}$ for the non-deformed and $543 \mathrm{~mm}^{-2} \cdot \mathrm{min}^{-1}$ for the deformed specimens. It is seen that when $30 \%$ rolling is applied the nucleation rate per unit area of grain boundary surface becomes about 27 times larger.

For enhancement of nucleation on grain boundaries by deformation, the following two reasons may be considered. One is the increase in the dislocation density in the matrix, and the second is the formation of many small regions on grain boundary where the boundary energy is high. The free energy change corresponding to the difference in the dislocation density between in the matrix and in the new phase is at the most $1 \mathrm{cal} / \mathrm{mol}$, even if we assume that the dislocation density in the work-hardened austenite is as high as $10^{10} \mathrm{~cm}^{-2}$. Thus no large increase in the nucleation rate may be expected by the introduction of dislocations by deformation.

When a specimen is deformed in the austenite condition the smooth and flat grain boundaries become wavy and irregular (serrated) as the result of the non-uniform slips occurring inside the grains. As a consequence many small regions with high grain boundary energy will be produced. Such regions may act as the preferential nucleation sites of pearlite. Thus, the formation of such regions by deformation is considered to be the most probable reason for the increase in the nucleation rate on the grain boundaries.

\section{The Effect of Austenite Deformation on the Nucleation of Pearlite within the Austenite Grains}

It has been well known that when deformation is applied below the recrystallization temperature, deformation bands are produced and these act as the additional nucleation sites in the subsequent diffusional transformation. Therefore the formation of deformation bands leads to the increase in the density of nucleation sites per unit volume. Kozasu et al. ${ }^{6}$ ) proposed to consider the effective austenite interfacial area, which is the overall interfacial area of the austenite grain boundaries and deformation bands, for the nucleation rate in the deformed specimen.

Table 2. The values of $\bar{l}, D, X$ and $G$ used in the calculation of $I_{g \cdot b}$ in both non-deformed and deformed specimen.

\begin{tabular}{l|l|ll}
\hline & & $\begin{array}{c}\text { not } \\
\text { rolled }\end{array}$ & $\begin{array}{c}30 \% \\
\text { rolled }\end{array}$ \\
\hline $\begin{array}{l}\text { Transformed at } 715^{\circ} \mathrm{C} \\
\text { for }\end{array}$ & $(\mathrm{min})$ & 60 & 30 \\
$\begin{array}{l}\text { Average linear inter- } \\
\text { cept length }\end{array}$ & $\tilde{l}(\mu \mathrm{m})$ & 68.0 & 71.0 \\
Nominal diameter & $D(\mu \mathrm{m})$ & 76.0 & 80.0 \\
Fraction transformed & $X$ & 0.187 & 0.284 \\
Growth rate & $G\left(\mu \mathrm{m} \cdot \mathrm{min}^{-1}\right)$ & 0.31 & 0.31 \\
\hline Nucleation rate & $I_{g \cdot b}\left(\mathrm{~mm}^{-2} \cdot \mathrm{min}^{-1}\right)$ & 20.3 & 543 \\
\hline
\end{tabular}

In the present study pearlite nucleations were clearly observed on deformation bands and also on annealing twin boundaries. The contribution of the nucleation at places other than austenite grain boundaries to the total transformed fraction was measured as follows. Using the optical micrographs taken from the specimens rolled $30 \%$ and transformed at $715^{\circ} \mathrm{C}$ for $30 \mathrm{~min}$, the transformed fraction of pearlite nucleated within the grains (nucleated on deformation bands, on annealing twin boundaries, and so on) and at the grain boundaries were measured separately with point counting method. The average pearlite fraction nucleated within the grains was found to be $25 \%$ of the total transformed fraction.

\section{Comparison of the Effects of Three Factors on the Acceleration of Transformation}

The effects of the above three factors on the acceleration of pearlite transformation will now be quantitatively compared as the effects on the decrease in the half reaction time. Figure 8 shows schematically the transformation curves of the specimens with four different austenite conditions defined in Fig. 5. The curves denoted (a) to (d) in Fig. 8 correspond to the austenite conditions (a) to (d) in Fig. 5, respectively.

Let us define the half reaction times for transformation curves (a) to (d) in Fig. 8 as $t_{0.5}, t_{0.5}^{\prime}, t_{0.5}^{\prime \prime}$ and $t_{0.5}^{\prime \prime \prime}$, respectively. Now the half reaction time for the non-deformed specimen can be obtained by substituting $X=0.5, \bar{l}=68 \mu \mathrm{m}, G=0.31 \mu \mathrm{m} \cdot \mathrm{min}^{-1}$ and $I_{g \cdot b}=20 \mathrm{~mm}^{-2} \cdot \mathrm{min}^{-1}$ into Eqs. (1) and (2). We obtain $t_{0.5}$ to be $87.2 \mathrm{~min}$.

The half reaction time $t_{0.5}^{\prime \prime \prime}$ for the austenite condition shown in Fig. 5(b) can be calculated as follows. The increased austenite grain surface area per unit volume by the elongation of grains may be expressed by the initial austenite grain boundary surface area multiplied by $q(p)$. Thus kinetic equation becomes

$$
\begin{aligned}
X= & 1-\exp \left\{-\frac{4 q(p)}{\bar{l}} G t \int_{0}^{1}\left(1-\exp \left\{-\pi I_{g \cdot b} G^{2} t^{3}\right.\right.\right. \\
& \left.\left.\left.\times\left[\left(1-x^{3}\right) / 3-x^{2}(1-x)\right]\right\}\right) d x\right\} \ldots \ldots \ldots \ldots \ldots \ldots \ldots \ldots \ldots \ldots \ldots \ldots \ldots
\end{aligned}
$$

Substituting $X=0.5, \quad \bar{l}=68 \mu \mathrm{m}, \quad G=0.31 \mu \mathrm{m} \cdot \mathrm{min}^{-1}$, $I_{g \cdot b}=20 \mathrm{~mm}^{-2} \cdot \mathrm{min}^{-1}$ and $q=1.04$ into Eq. (6), we obtain $t_{0.5}^{\prime}$ to be $86.1 \mathrm{~min}$.

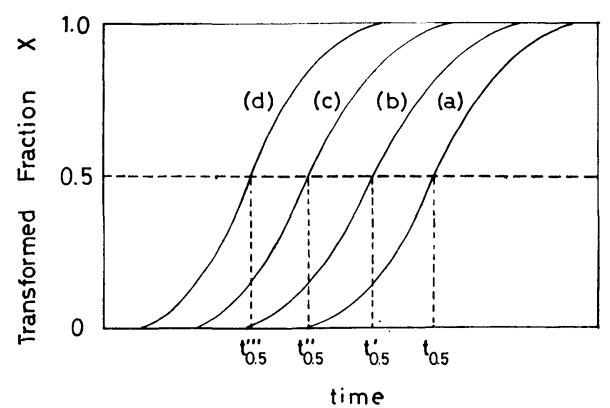

Fig. 8. Schematic transformation curves. The curves (a) to (d) correspond to the austenite condition (a) to (d) in Fig. 5. 
The half reaction time $t_{0.5}^{\prime \prime}$ for the austenite condition shown in Fig. 5(c) may be calculated from Eq. (6) by substituting $X=0.5, \tilde{l}=68 \mu \mathrm{m}, G=0.31 \mu \mathrm{m}$. $\min ^{-1}, q=1.04$ and $I_{g \cdot b}=543 \mathrm{~mm}^{-2} \cdot \mathrm{min}^{-1}$. The $t_{0.5}^{\prime \prime}$ is $47.8 \mathrm{~min}$.

The half reaction time $t_{0.5}^{\prime \prime \prime}$ for the austenite condition shown in Fig. 5(d) may be calculated as follows. Since about $25 \%$ of the total pearlite is formed within the grains, the pearlite fraction nucleated on grain boundaries when the half reaction is completed is $0.375(=0.5 \times 0.75)$. Substituting $X=0.375, \bar{l}=68 \mu \mathrm{m}$, $G=0.31 \mu \mathrm{m} \cdot \mathrm{min}^{-1}, \quad q=1.04$ and $I_{g \cdot b}=543 \mathrm{~mm}^{-2}$. $\mathrm{min}^{-1}$ into Eq. (6), we obtain $t_{0.5}^{\prime \prime \prime}$ to be $38.4 \mathrm{~min}$.

The individual effect of the three factors on the acceleration of pearlite transformation may be expressed by taking the ratio of the half reaction times. Let us define the acceleration multiplying factors $f_{g}, f_{I}$ and $f_{d \cdot b}$ as

$$
f_{g}=t_{0.5}^{\prime} / t_{0.5}, \quad f_{I}=t_{0.5}^{\prime \prime} / t_{0.5}^{\prime} \quad \text { and } f_{d \cdot b}=t_{0.5}^{\prime \prime \prime} / t_{0.5}^{\prime \prime}
$$

Then $f_{g}$ indicates the decrease of the half reaction time due only to the elongation of grains, $f_{I}$ indicates that only to the increase in the rate of nucleation on grain boundaries, and $f_{a \cdot b}$ indicates that only to the formation of additional nucleation sites within grains. Using the calculated values of $t_{0.5}, t_{0.5}^{\prime}, t_{0.5}^{\prime \prime}, t_{0.5}^{\prime \prime}$, the values of $f_{g}, f_{I}$ and $f_{d \cdot b}$ were obtained as

$$
f_{g}=0.99, f_{I}=0.56 \text { and } f_{d \cdot b}=0.80
$$

It is clear that on the acceleration of austenite $\rightarrow$ pearlite transformation by $30 \%$ rolling in the steel studied, the effect of the increase in the nucleation rate per unit area of grain boundary surface is dominant, and that this effect is about 2.3 times $\left(\left(1-f_{I}\right) /\right.$ $\left.\left(1-f_{d \cdot b}\right)=2.3\right)$ larger than that of the formation of additional nucleation sites such as deformation bands. The effect of the increase of the grain boundary surface area by the elongation of grains on the acceleration of pearlite transformation is quite small at such a small rolling reduction.

\section{Estimation of the Effect of Rolling Reduction $p$ on the Transformation Kinetics}

The effect of the rolling reduction $p$ on the transformation kinetics of pearlite in the steel studied will now be considered.

For simplicity we assume;

(1) that the additional nucleation sites produced by deformation are the deformation bands only,

(2) that the nucleation rate per unit area of deformation band is equal to that of the grain boundary surface,

(3) that the nucleation rate on the grain boundary surface, $I_{g \cdot b}$, is a linear function of strain $\varepsilon(=-\ln$ $(1-p))$, i.e.,

$$
I_{g \cdot b}(p)=I_{g \cdot b}(p=0)+A \ln (1-p)
$$

where, $A$ is a constant, and

(4) that the deformation band density $S_{d \cdot b}$ is quadratic with respect to the strain $\varepsilon$, i.e.,

$$
S_{d \cdot b}(p)=B\{\ln (1-p)\}^{2}
$$

where $B$ is a constant, according to the experimental data reported by Kozasu et al. ${ }^{6}$ )

From the assumptions (1) and (2) we obtain a kinetic equation for the deformed specimens as

$$
\begin{aligned}
& X=1-\exp \left[-2\left\{\frac{2 q(p)}{\bar{l}}+S_{d \cdot b}(p)\right\} G t\right. \\
& \times \int_{0}^{1}\left(1-\exp \left\{-\pi I_{g \cdot b} G^{2} t^{3}\left[\left(1-x^{3}\right) / 3\right.\right.\right. \\
& \left.\left.\left.\left.-x^{2}(1-x)\right]\right\}\right) d x\right]
\end{aligned}
$$

or using the ASTM nominal grain diameter $D$ (Eq. (3)) as

$$
\begin{aligned}
& X=1-\exp \left[-2\left\{\frac{2.245 q(p)}{D}+S_{d \cdot b}(p)\right\} G t\right. \\
& \times \int_{0}^{1}\left(1-\exp \left\{-\pi I_{g \cdot b} G^{2} t^{3}\left[\left(1-x^{3}\right) / 3\right.\right.\right. \\
& \left.\left.\left.\left.-x^{2}(1-x)\right]\right\}\right) d x\right] \text {. }
\end{aligned}
$$

The nucleation rate per unit area of grain boundary in the steel studied can be expressed as a function of $p$ as follows. When $p=0$ and 0.3 , the nucleation rates per unit area of grain boundary were measured as $20.3 \mathrm{~mm}^{-2} \cdot \mathrm{min}^{-1}$ and $543 \mathrm{~mm}^{-2} \cdot \mathrm{min}^{-1}$, respectively. From the assumption (3), $I_{a \cdot b}(p)$ can be expressed as

$$
\begin{array}{r}
I_{g \cdot b}(p)=2.03 \times 10^{-5}-1.47 \times 10^{-3} \ln (1-p) \\
\quad\left(\mu \mathrm{m}^{-2} \cdot \min ^{-1}\right)
\end{array}
$$

The deformation band density $S_{d \cdot b}$ in the steel studied can be expressed as a function of $p$ as follows. Remembering that $25 \%$ of the transformed portion is formed on deformation band when the total transformed fraction is 0.5 , one may express the deformation band density from the assumption (4) as

$$
S_{d \cdot \delta}(p)=0.114\{\ln (1-p)\}^{2} \quad\left(\mu \mathrm{m}^{-1}\right) \ldots
$$

Substituting $q(p), I_{g \cdot b}(p)$ and $S_{d \cdot b}(p)$ into Eq. (11), the half reaction times $t_{0.5}, t_{0.5}^{\prime}, t_{0.5}^{\prime \prime}$ and $t_{0.5}^{\prime \prime \prime}$ defined in Fig. 8 can be calculated and $f_{g}, f_{I}$ and $f_{d \cdot b}$ can be obtained as a function of $p$.

Figure 9 shows the variation of $f_{g}, f_{I}$ and $f_{d \cdot b}$ as a function of $p$. In this figure, the total change in the half reaction time $F\left(t_{0.5}^{\prime \prime \prime} / t_{0.5}\right)$ is also shown. It is seen that in the steel studied the acceleration of the pearlite transformation would be mostly attributed to the increase in the rate of nucleation on the grain boundary surface for the whole range of rolling reduction $p$. The contribution of the formation of deformation band would increase with increase in $p$ but should saturate at around 0.6 after $p$ becomes larger than 0.6.

\section{Estimation of the Influence of Austenite Grain Size on the Acceleration Mechanism of Transformation by Deformation}

As discussed above, in the steel studied the ac- 


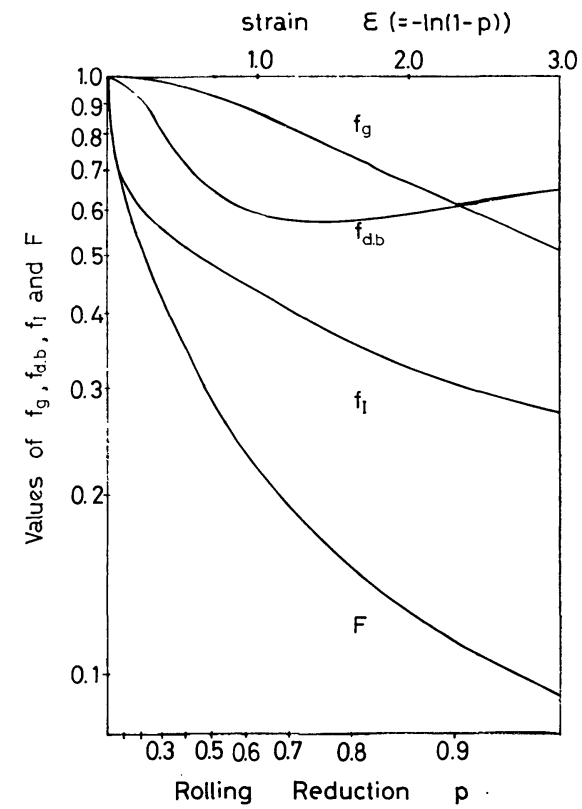

Fig. 9. Estimated variation of $f_{g}, f_{I}, f_{d \cdot b}$ and $F$ as a function of $p$ in the steel studied.

celeration of transformation is mostly attributed to the increase in the nucleacion rate per unit area of grain surface. However, this may not be true for all the grain sizes. As the austenite grain size becomes large, the density of nucleation sites per unit volume of specimen becomes small, and at the same time the site saturation becomes easy to occur. Then it is expected that when the austenite grain size becomes large the acceleration of transformation is attributed more to the formation of deformation bands and less to the increase in the nucleation rate per unit area of grain surface.

The effect of austenite grain size on the values of $f_{g}, f_{I}$ and $f_{d \cdot b}$ in the steel studied were calculated using Eqs. (11) to (14). Figure 10 shows the variation of $f_{g}, f_{I}$ and $f_{d \cdot b}$ as a function of grain diameter $D$ when the rolling reduction is 0.3 . In this figure, the total change in the half reaction time $F$ ( $=f_{g} \cdot f_{I} \cdot f_{d \cdot b}$ ) is also shown. As is seen, the values of $f_{g}$ is almost insensitive to $D$, but $f_{I}$ and $f_{d \cdot b}$ are quite sensitive to $D$. When $D$ is small the value of $f_{d \cdot b}$ is larger than $f_{I}$, and when $D$ is large $f_{I}$ is larger than $f_{d \cdot b}$. The curves of $f_{I}$ and $f_{d \cdot b}$ intersect each other at around $D=126 \mu \mathrm{m}$ in this particular case. Thus it is expected that in the steel studied when the austenite grain diameter is smaller than $126 \mu \mathrm{m}$ the effect of the increase in the nucleation rate per unit area of grain surface is largest, and when the austenite grain diameter is larger than $126 \mu \mathrm{m}$, the effect of the formation of deformation bands is the largest on the acceleration of transformation. It is also seen that in total the pearlite transformation is more accelerated by deformation (i.e., $F$ is smaller) in a large grained specimen.

Another important factor which influences the acceleration mechanism of transformation is the ratio of the nucleation rate to the growth rate $I_{g \cdot b} / G$. As is shown in Appendix, the condition at which more than half of the nucleation sites (grain boundaries) are

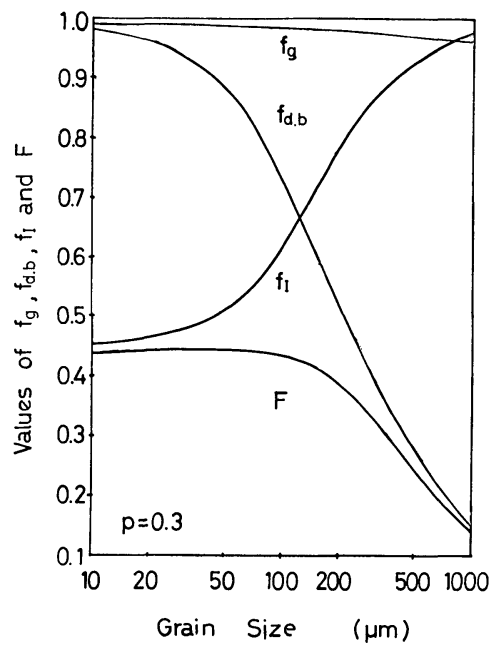

Fig. 10. Estimated variation of $f_{g}, f_{I}, f_{d \cdot b}$ and $F$ as a function of austenite grain size $D$ in the steel studied when $p=0.3$.

occupied by the new phase, when the reaction is half completed, is given from Eq. (1) as,

$$
I_{g \cdot b} \cdot D^{3} / G>3.6
$$

Thus as the ratio $I_{g \cdot b} / G$ and the grain diameter $D$ becomes large, the transformation condition becomes close to site saturation and the effect of the increase in the nucleation rate per unit area of grain surface on the acceleration of transformation becomes small. In summary, it may be concluded that the effect of the formation of deformation bands on the acceleration of transformation becomes large when the austenite grain size becomes large. The effect of the increase in the nucleation rate per unit area of grain surface on the acceleration of transformation becomes small when the value of $I_{g \cdot b} \cdot D^{3} / G$ becomes larger than 3.6 .

\section{Conclusions}

To understand the effect of austenite deformation below its recrystallization temperature on the subsequent isothermal transformation, the pearlite transformation in the steel SKD 6 after $30 \%$ rolling in austenite condition was investigated. The main results obtained were as follows:

(1) The austenite $\rightarrow$ pearlite transformation was markedly accelerated by the deformation.

(2) The growth rate was found out to be unaltered by the deformation.

(3) In the deformed specimen, annealing twin boundaries and deformation bands were observed to act as the additional nucleation sites.

(4) The rate of nucleation on the grain boundary surface was estimated to be increased about 27 times by $30 \%$ rolling.

(5) The increase in the nucleation rate per unit volume of specimen by the deformation is attributed; 1) to the increase in the austenite grain surface area by the elongation of grains, 2) to the increase in the nucleation rate per se per unit area of grain surface, and 3 ) to the formation of additional nucleation 
sites such as deformation bands. Simple calculation indicated that among these the increase in the nucleation rate per se per unit area of grain surface contributes the greatest to the acceleration of transformation when the austenite grain size is large, and the effect of the formation of deformation bands is the largest on the acceleration of transformation when the grain size is small.

(6) In general, when the specimen is near the condition of site saturation $\left(I_{g \cdot b} \cdot D^{3} / G>3.6\right)$ the transformation is accelerated most by the formation of deformation bands and less by the increase in the nucleation rate per unit area of grain surface.

\section{REFERENGES}

1) V.F. Zackay and M. Justusson: High-Strength steels, Iron Steel Inst., London, (1962), 14.

2) R. W. Vanderbeck: Welding J., 37 (1958), 114.

3) T. Gladman and D. Dulieu: Metal Sci., 8 (1974), 167.

4) T. Tanaka, T. Tabata, T. Hatomura and C. Shiga: Proceedings of Microalloying 75, Union Carbide Corp., New York, (1975), 107.

5) D. J. Walker and R.W.K. Honeycombe: Metal Sci., 12 (1978), 445.

6) I. Kozasu, C. Ouchi, T. Sampei and T. Okita: Proceedings of Microalloying 75, Union Carbide Corp., New York, (1975), 100.

7) M. S. Sulonen: Acta Met., 12 (1964), 749.

8) H. Weissenberg and E. Hornbogen: Arch Eisenhüttenw., 50 (1979), 479.

9) L. Kaufman, S. V. Radcliffe and M. Cohen: Decomposition of Austenite by Diffusional Processes, John Wiley \& Sons, Pennsylvania, (1962), 313.

10) C. Zener: Trans. AIME, 167 (1946), 550.

11) J. W. Cahn: Acta Met., 4 (1956), 449.

12) S. A. Saltykov: Stereometric Metallography, 2nd ed., Metallurgizdat, Moscow, (1958), 446.

13) ASTM Designation E112.
14) M. Umemoto, N. Komatsubara and I. Tamura: J. Heat Treating, 1 (1980), No. 3, 57.

\section{Appendix}

The fraction transformed $X$ for the reaction in which the new phase nucleated on grain boundary surface is given from Eqs. (1) to (3) as

$$
\begin{aligned}
X= & 1-\exp \left\{-\frac{4.49}{D} G t \int_{0}^{1}\left(1-\exp \left\{-\pi I_{g \cdot b} G^{2} t^{3}\right.\right.\right. \\
& \left.\left.\left.\times\left[\left(1-x^{3}\right) / 3-x^{2}(1-x)\right]\right\}\right) d x\right\} \quad \ldots \ldots \ldots \ldots \ldots \ldots . . . .
\end{aligned}
$$

The fraction of grain boundary surface occupied by the new phase, $Y_{s}$, is

$$
Y_{s}=1-\exp \left(-\frac{\pi}{3} I_{g \cdot b} G^{2} t^{3}\right)
$$

The condition at which more than half of the nucleation sites are occupied by the new phase when reaction is half completed is given as

$$
Y_{s}>0.5 \text { or } \pi I_{g \cdot b} G^{2} t^{3}>3 \ln 2 \quad \text { when } \quad X=0.5
$$

Substituting this condition into Eqs. (A-1) and (A-2), we obtain

$$
\begin{aligned}
0.5> & 1-\exp \left\{-\frac{4.49}{D} G t \int_{0}^{1}(1-\exp \{-3 \ln 2\right. \\
& \left.\left.\left.\times\left[\left(1-x^{3}\right) / 3-x^{2}(1-x)\right]\right\}\right) d x\right\}
\end{aligned}
$$

or

$$
G t / D>0.57
$$

From Eqs. (A-3) and (A-4)

$$
I_{g \cdot b} D^{3} / G>3.6
$$

